\title{
Bufalin sensitizes human bladder carcinoma cells to TRAIL-mediated apoptosis
}

\author{
KYUNG-HWA KANG ${ }^{1}$, MIN HO HAN ${ }^{2}$, JIN-WOO JEONG ${ }^{3,4}$, CHEOL PARK $^{5}$, SANG-HYUP LEE ${ }^{6}$,

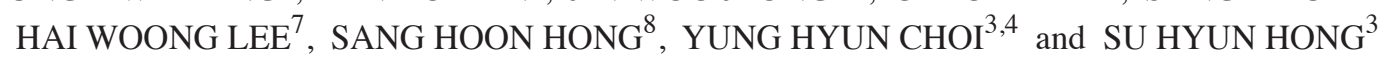 \\ ${ }^{1}$ Department of Physiology, Dongeui University College of Korean Medicine, Busan 614-052; \\ ${ }^{2}$ Natural Products Research Team, National Marine Biodiversity Institute of Korea, Seocheon, \\ South Chungcheong 325-902; ${ }^{3}$ Department of Biochemistry, Dongeui University College of Korean Medicine, \\ Busan 614-052; ${ }^{4}$ Anti-Aging Research Center \& Blue-Bio Industry RIC; Dongeui University; \\ ${ }^{5}$ Department of Molecular Biology, College of Natural Science and Human Ecology, Dongeui University, \\ Busan 614-714; Departments of ${ }^{6}$ Korean Medical Classics, ${ }^{7}$ Public Health and ${ }^{8}$ Internal Medicine, \\ Dongeui University College of Korean Medicine, Busan 614-052, Republic of Korea
}

Received January 18, 2016; Accepted March 28, 2017

DOI: $10.3892 / 01.2017 .6223$

\begin{abstract}
Tumor necrosis factor (TNF)-related apoptosis-inducing ligand (TRAIL), a member of the TNF superfamily, has garnered interest as it is relatively non-toxic to normal cells, but selectively induces apoptotic cell death in multiple types of transformed or malignant cells. Bufalin is the major digoxin-like immunoreactive component of Sum Su, which is obtained from the skin and parotid venom gland of the toad. Bufalin is known to inhibit cell proliferation and induce apoptosis in a variety of cancer cells. The present study investigated whether bufalin promoted TRAIL-induced apoptotic cell death. In the present study, a combined treatment using bufalin and TRAIL significantly increased TRAIL-mediated inhibition of cell viability and increased apoptosis in T24 human bladder cancer cells. The apoptotic effects were associated with the upregulation of death receptor proteins and the downregulation of cellular Fas-associated death domain-like interleukin-1 $\beta$-converting enzyme inhibitory protein and $\mathrm{X}$-linked inhibitor of apoptosis protein. Furthermore, the data revealed that bufalin and TRAIL activated caspase-3, -8 and -9 and subsequently increased the degradation of poly (ADP-ribose) polymerase. Taken altogether, the nontoxic doses of bufalin and TRAIL sensitized T2 4 cells to TRAIL-mediated apoptosis. Therefore, bufalin may provide an effective therapeutic strategy for the safe treatment of human bladder cancers that are resistant to TRAIL.
\end{abstract}

Correspondence to: Professor Su Hyun Hong, Department of Biochemistry, Dongeui University College of Korean Medicine, 52-57 Yangjeong Street, Busan 614-052, Republic of Korea

E-mail: hongsh@deu.ac.kr

Key words: bufalin, tumor necrosis factor-related apoptosisinducing ligand, apoptosis, caspase, bladder cancer

\section{Introduction}

Tumor necrosis factor (TNF)-related apoptosis-inducing ligand (TRAIL), also known as Apo2L and TNFSF10, is a type II transmembrane protein belonging to the TNF superfamily that is able to induce programmed cell death $(1,2)$. TRAIL-mediated apoptosis follows binding to its receptors: Death receptor 4 (DR4, also known as TRAIL-R1 and TNFRSF10a) and DR5 (also known as TRAIL-R2 and TNFRSF10b), which contain an intracellular death domain and transmit apoptotic signals to intracellular apoptosis-associated proteins $(3,4)$. TRAIL has been the center of attention as it is relatively non-toxic to normal cells, but selectively induces apoptotic cell death in multiple types of transformed or malignant cells $(1,5)$. However, certain malignant cells are resistant to TRAIL $(6,7)$. Therefore, finding novel reagents that are able to promote TRAIL-induced apoptosis in cancer cells is useful to increase the effects of TRAIL-based cancer therapy, or to overcome TRAIL resistance.

Bladder cancer is one of the most common genitourinary malignant neoplasms and is typically observed in older patients (8). According to the growth of aging populations worldwide, the occurrence of bladder cancer is expected to increase $(8,9)$. To develop improved treatments, multiple studies have been conducted to detect drugs that sensitize bladder cancer to TRAIL-induced apoptosis $(10,11)$. Previous research has also demonstrated that a combination of chemotherapy or natural agents with TRAIL triggers apoptosis through the upregulation of DRs, activation of caspases, the downregulation of survival proteins including cellular Fas-associated death domain-like interleukin-1 $\beta$-converting enzyme inhibitory protein (cFLIP) and X-linked inhibitor of apoptosis protein (XIAP), and the modification of B cell lymphoma-2 (Bcl-2) family proteins (12-14). Therefore, the resistance of bladder cancer cells to TRAIL may be overcome by the use of sensitizing chemicals that alter the dysregulated expression of DRs and apoptosis-associated proteins (15). 
Bufalin is a major component of Sum Su, which is a traditional oriental medicine obtained from the skin and parotid venom gland of the toad. Bufalin possesses various biological properties, acting as a cardiotonic, an anesthetic and a blood pressure stimulant, as well as demonstrating respiration-improving and anti-neoplastic activities $(16,17)$. In terms of its anti-tumor activities, bufalin has been demonstrated to suppress cell proliferation and to cause apoptosis in a wide spectrum of cancer cells, including lung adenocarcinoma cells, prostate cancer cells, ovarian cancer cells, gastric cancer cells, bladder cancer cells, hepatocellular cells, breast cancer and leukemia cells (16-20). On the other hand, only 2 previous studies concerning the use of bufalin as a sensitizing reagent to overcome TRAIL resistance in breast cancer have been conducted. Yan et al $(12,21)$ demonstrated that bufalin enhanced TRAIL-induced apoptosis of breast cancer cells via upregulation of the DRs in vitro and in vivo. However, to the best of our knowledge, a combination treatment including bufalin and TRAIL is yet to be attempted in bladder carcinoma cells.

Therefore, the present study investigated whether bufalin promoted TRAIL-induced apoptotic cell death and was able to overcome resistance to TRAIL in human bladder cancer cells, and focused on understanding the underlying molecular mechanisms. In the present study, bufalin was demonstrated to markedly sensitize bladder cancer cells to TRAIL-induced apoptosis.

\section{Materials and methods}

Reagents and antibodies. MTT, propidium iodide (PI) and DAPI were purchased from Sigma-Aldrich; Merck KGaA (Darmstadt, Germany). RPMI-1640 medium, fetal bovine serum (FBS) and penicillin/streptomycin were purchased from Gibco; Thermo Fisher Scientific, Inc. (Waltham, MA, USA). TRAIL was obtained from Koma Biotech (Seoul, Korea) and dissolved in phosphate buffered saline (PBS) to $10 \mathrm{mg} / \mathrm{ml}$ and stored at $-70^{\circ} \mathrm{C}$. Bufalin was purchased from Sigma-Aldrich; Merck KGaA. The formula weight was $386.52 \mathrm{~g} / \mathrm{mol}$ and the purity was $>97 \%$, as determined by high performance liquid chromatography. Bufalin was dissolved in dimethyl sulfoxide (DMSO; vehicle) to a concentration of $10 \mathrm{mM}$. Further dilutions of TRAIL and bufalin were made in RPMI culture medium prior to use. Antibodies against Bcl-2-associated X (Bax; cat. no. sc-493), Bcl-2 (cat. no. sc-782), BH3 interacting domain death agonist (Bid; cat. no. sc-11423), XIAP (cat. no. sc-11426), cFLIP (cat. no. sc-5276), DR5 (cat. no. sc-65314), DR4 (cat. no. sc-7863), caspase-3 (cat. no. sc-7272), caspase-9 (cat. no. sc-7885), caspase-8 (cat. no. sc-7890), poly (ADP-ribose) polymerase (PARP; cat. no. sc-1562), $\beta$-actin (cat. no. sc-1616) (all dilutions, 1:1,000) and peroxidase-labeled goat anti-rabbit (cat. no. sc-2004), goat anti-mouse (cat. no. sc-2005) and cow anti-goat (cat. no. sc-2350; all dilution, 1:1,500) IgG were purchased from Santa Cruz Biotechnology, Inc. (Dallas, TX, USA). All other chemicals were purchased from Sigma-Aldrich (Merck $\mathrm{KGaA}$ ) unless otherwise indicated.

Cell lines and cell culture. The human bladder carcinoma T24 cell line was obtained from the American Type Culture Collection (Manassas, VA, USA), and cultured in RPMI-1640 medium supplemented with $10 \%$ heat-inactivated FBS, 2 mM glutamine, $100 \mathrm{U} / \mathrm{ml}$ penicillin and $100 \mu \mathrm{g} / \mathrm{ml}$ streptomycin at $37^{\circ} \mathrm{C}$ and $5 \% \mathrm{CO}_{2}$.

MTT assay and cell morphological analysis. To measure cell viability, an MTT assay was conducted. The T24 cells were seeded at a density of $1 \times 10^{5}$ cells/well in 6-well plates, and treated with bufalin $(0,5$ or $10 \mathrm{nM})$, TRAIL $(0,25$ or $50 \mathrm{ng} / \mathrm{ml}$ ) or a combination. Following $24 \mathrm{~h}$ incubation at $37^{\circ} \mathrm{C}$ with $5 \% \mathrm{CO}_{2}$, the medium was removed, and the cells were incubated with $0.5 \mathrm{mg} / \mathrm{ml}$ MTT solution for $2 \mathrm{~h}$. Then, the supernatant was discarded and the formazan crystals were dissolved with DMSO. The optical density was measured by a microplate reader (Dynatech Laboratories, Inc., Chantilly VA, USA) at $540 \mathrm{~nm}$. The cell images were taken with an inverted light microscope (Carl Zeiss AG, Oberkochen, Germany) at a magnification of $\times 50$.

Nuclear staining with DAPI. T24 cells were seeded at a density of $1 \times 10^{5}$ cells/well in 6-well plates and treated with bufalin (10 nM), TRAIL (50 ng/ml), a combination, or neither, and incubated for $24 \mathrm{~h}$ at $37^{\circ} \mathrm{C}$ with $5 \% \mathrm{CO}_{2}$. The cells were then harvested with trypsin, washed once with cold PBS and centrifuged at $500 \mathrm{x} \mathrm{g}$ at $4^{\circ} \mathrm{C}$ for $5 \mathrm{~min}$. The cells were fixed with $3.7 \%$ paraformaldehyde (Sigma-Aldrich; Merck KGaA) in PBS at room temperature for $10 \mathrm{~min}$. Next, the fixed cells were washed with PBS and stained with $2.5 \mu \mathrm{g} / \mathrm{ml}$ DAPI solution at room temperature for $10 \mathrm{~min}$. The nuclear morphology of the cells was observed by a fluorescence microscope (Carl Zeiss AG) at a magnification of x200.

Cell cycle analysis. T24 cells $\left(1 \times 10^{5}\right)$ cells/well in 6-well plates were treated with bufalin $(10 \mathrm{nM})$, TRAIL $(50 \mathrm{ng} / \mathrm{ml})$, a combination, or neither, and incubated for $24 \mathrm{~h}$ at $37^{\circ} \mathrm{C}$ with $5 \% \mathrm{CO}_{2}$. The cells were harvested with trypsin and washed once in PBS. Subsequent to centrifugation at $500 \mathrm{xg}$ and $4^{\circ} \mathrm{C}$ for $5 \mathrm{~min}$, the pellets were fixed in $70 \%$ ethanol and stored at $4^{\circ} \mathrm{C}$ for $1 \mathrm{~h}$. Prior to the analysis, the cells were washed once again with PBS and suspended in $1 \mathrm{ml}$ cold PI solution containing $100 \mu \mathrm{g} / \mathrm{ml}$ RNase A, $50 \mu \mathrm{g} / \mathrm{ml}$ PI, $0.1 \%$ (w/v) sodium citrate and $0.1 \%(\mathrm{v} / \mathrm{v})$ nonidet $\mathrm{p} 40$, then incubated on ice for $30 \mathrm{~min}$ in the dark. Flow cytometric analysis was performed using a flow cytometer (FACSCalibur) with CellQuest software (version 6; both BD Biosciences, Franklin Lakes, NJ, USA) was used to estimate the relative DNA content based on the presence of a red fluorescence. The sub-G1 population was calculated to estimate the apoptotic cell population.

Protein extraction and western blot analysis. T24 cells $\left(5 \times 10^{5}\right)$ were seeded in 100-mm plates, treated with bufalin (10 nM), TRAIL (50 ng/ml), a combination, or neither, and incubated for $24 \mathrm{~h}$ at $37^{\circ} \mathrm{C}$ with $5 \% \mathrm{CO}_{2}$. The cells were washed with ice-cold PBS and lysed with a lysis buffer $(20 \mathrm{mM}$ sucrose, $1 \mathrm{mM}$ EDTA, $20 \mu \mathrm{M}$ Tris-Cl, pH 7.2, $1 \mathrm{mM}$ dithiothreitol (DTT), $10 \mathrm{mM}$ $\mathrm{KCl}, 1.5 \mathrm{mM} \mathrm{MgCl}_{2}$, and $5 \mu \mathrm{g} / \mathrm{ml}$ aprotinin) for $30 \mathrm{~min}$ on ice. The lysis mixture was centrifuged at $13,453 \mathrm{x} \mathrm{g}$ and $4^{\circ} \mathrm{C}$ for $15 \mathrm{~min}$ to remove cell debris. Supernatant liquid was collected and protein concentration was quantified using a Bio-Rad protein assay kit (Bio-Rad Laboratories, Inc., Hercules, CA, USA) according to the manufacturer's protocol. For western 
blot analysis, equal amounts of protein $(30 \mu \mathrm{g})$ were subjected to electrophoresis on $8-12 \%$ of SDS-polyacrylamide gel (depending on the molecular weight of the antibody target) and then electrotransferred to a nitrocellulose membrane for $2 \mathrm{~h}$ at $4^{\circ} \mathrm{C}$ (Schleicher \& Schuell Bioscience, Inc., Keene, NH, USA). The blots were probed with the primary antibodies, incubated with the diluted enzyme-linked secondary antibodies. The blot was visualized using an enhanced chemiluminescence western blotting detection reagent (GE Healthcare Life Sciences, Chalfont, UK), observed with a UV transilluminator imaging system and analyzed with CAPT 2000 software (version 12.8; both Vilber Lourmat, Collégien, France).

Determination of caspase activity. T24 cells were seeded at a density of $1 \times 10^{5}$ cells/well in 6-well plates and treated with bufalin $(10 \mathrm{nM})$, TRAIL $(50 \mathrm{ng} / \mathrm{ml})$, a combination, or neither, and incubated for $24 \mathrm{~h}$ at $37^{\circ} \mathrm{C}$ with $5 \% \mathrm{CO}_{2}$. Caspase-3, -8 and -9 activity levels were the measured using colorimetric assay kits (R\&D Systems, Inc., Minneapolis, MN, USA) according to the manufacturer's protocol. Briefly, the cells were lysed in the supplied lysis buffer from the kits. The supernatant liquid was collected and incubated with the supplied reaction buffer, containing DTT and colorimetric tetrapeptides as follows: An Asp-Glu-Val-Asp-p-nitroaniline (pNA) substrate for caspase-3, an Ile-Glu-Thr-Asp-pNA substrate for caspase- 8 and a Leu-Glu-His-Asp-pNA substrate for caspase- 9 , respectively, at $37^{\circ} \mathrm{C}$. The extent of reaction was measured as absorbance at $405 \mathrm{~nm}$ using an ELISA reader.

Statistical analysis. All data are presented as the mean \pm standard deviation. The significant differences between the groups were analyzed using unpaired Student's t-tests. $\mathrm{P}<0.05$ was considered to indicate a statistically significant difference. The results depicted in each of the figures were obtained from representatives of $\geq 2$ independent experiments.

\section{Results}

Combined bufalin and TRAIL treatment significantly inhibits T24 cell viability. Initially, the present study sought to determine whether a combination of bufalin and TRAIL treatment inhibited the viability of T24 cells using the MTT assay. For the present study, the cells were treated with bufalin (5 or $10 \mathrm{nM}$ ), TRAIL (25 or $50 \mathrm{ng} / \mathrm{ml}$ ), both agents (bufalin $5 \mathrm{nM}$ with TRAIL $25 \mathrm{ng} / \mathrm{ml}$ or $10 \mathrm{nM}$ with $50 \mathrm{ng} / \mathrm{ml}$ ), or neither, for $24 \mathrm{~h}$. Treatment with bufalin and TRAIL alone did not significantly affect cell viability; however, the combination of bufalin with TRAIL significantly reduced the viability of T24 cells (Fig. 1) compared with the negative control. Collectively, these results verified that a combination of bufalin and TRAIL was more effective together than either agent alone in decreasing the viability of bladder cancer cells.

Bufalin sensitizes TRAIL-resistant T24 cells to TRAILmediated apoptosis. Next, the present study investigated whether the inhibition of cell viability as a result of a combined treatment of bufalin and TRAIL was associated with apoptosis. Specific apoptotic features were observed by microscopy and flow cytometry, and T24 cells were treated with bufalin $(10 \mathrm{nM})$, TRAIL $(50 \mathrm{ng} / \mathrm{ml})$, or a combination

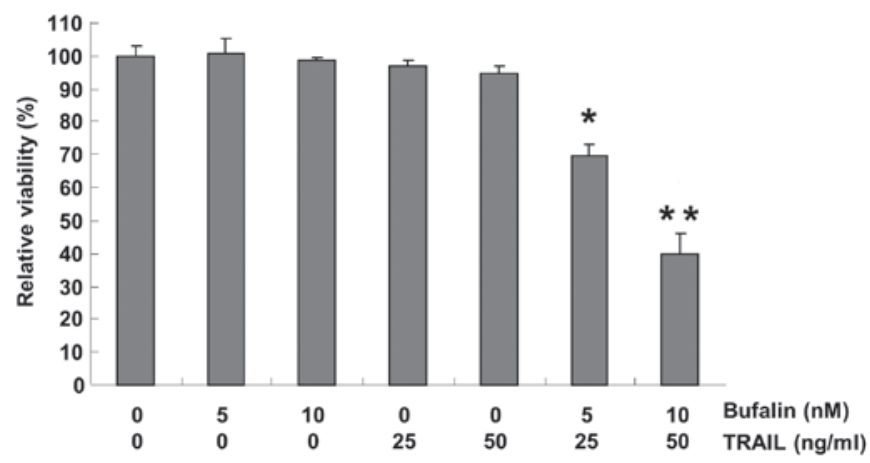

Figure 1. Inhibition of cell viability by co-treatment with bufalin and TRAIL in t24 human bladder carcinoma cells. Cell viability was assessed using the metabolic-dye based MTT assay. The data are expressed as the mean \pm standard deviation of three independent experiments. ${ }^{*} \mathrm{P}<0.05$ and ${ }^{* *} \mathrm{P}<0.01$ vs. untreated cells. TRAIL, tumor necrosis factor-related apoptosis-inducing ligand.

of the two for $24 \mathrm{~h}$. Direct observation using inverted microscopy revealed that morphological changes and decreased cell density compared with the negative control occurred in only the group treated with a combination of bufalin and TRAIL (Fig. 2A). In addition, while there was little change when cells were treated with either bufalin or TRAIL, cells demonstrated visibly increased chromatin condensation in the nuclei and increased formation of apoptotic bodies following combined treatment compared with the negative control (Fig. 2B). To further examine apoptosis, the size of the sub-G1 cell pool was measured. A total of $3.14 \%$ sub-G1 cells were measured following bufalin treatment, $4.10 \%$ following TRAIL treatment and $23.70 \%$ following combined treatment in T24 cells (Fig. 2C). These experiments indicated that bufalin and TRAIL synergistically stimulated TRAIL-mediated apoptosis in T24 cells.

Bufalin upregulates the expression of DR5 in T24 cells. DR4 and DR5 are expressed in the membrane of multiple cancer cell lines, and the ligation of TRAIL to DR4 or DR5 allows the initiation of the apoptosis pathway (22). To certify the mechanism of bufalin as a single agent capable of inducing apoptosis on the expression of DR4 and DR5 in T24 cells, T24 cells were exposed to $0,2.5,5,7.5$ or $10 \mathrm{nM}$ bufalin, or $10 \mathrm{nM}$ bufalin for $0,3,6,12$ or $24 \mathrm{~h}$, and western blot analysis was performed. Bufalin treatment visibly increased DR5 and DR4 protein levels in T24 cells (Fig. 3). Consistently, treatment with bufalin enhanced DR5 protein levels, but not DR4 protein levels, following treatment with the indicated concentrations (Fig. 3) Taken together, these results suggested that bufalin-induced apoptosis was involved in the upregulation of DR5 protein levels in T24 cells.

Combination treatment with bufalin and TRAIL modifies the expression of apoptosis-related proteins. In order to confirm the molecular mechanisms underlying these effects, the modulation of apoptosis-associated proteins was evaluated with western blot analysis, to examine whether a combined bufalin and TRAIL treatment induced apoptosis by modulating the expression of $\mathrm{Bcl}-2$ family members, which are important proteins for a wide array of diverse upstream 
A

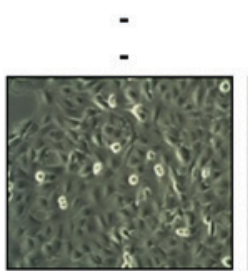

B
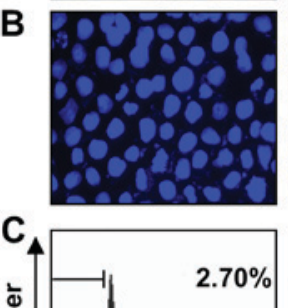
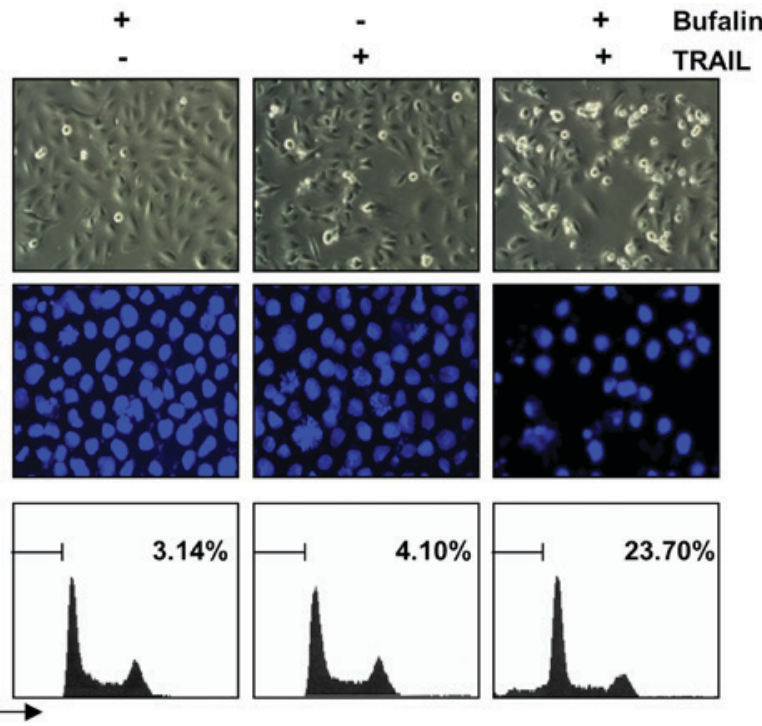

DNA content

Figure 2. Morphological changes and apoptotic formation following co-treatment with bufalin and TRAIL in human bladder cancer cells. (A) The morphological changes of the cells were observed using an inverted microscope (magnification, x50). (B) The cells were stained with a DAPI solution for 10 min and the stained nuclei were observed under a fluorescent microscope using a blue filter (magnification, x400). (C) Flow cytometric analysis was performed to analyze the sub-G1 DNA content. Each experiment was performed at least in triplicate. TRAIL, tumor necrosis factor-related apoptosis-inducing ligand.
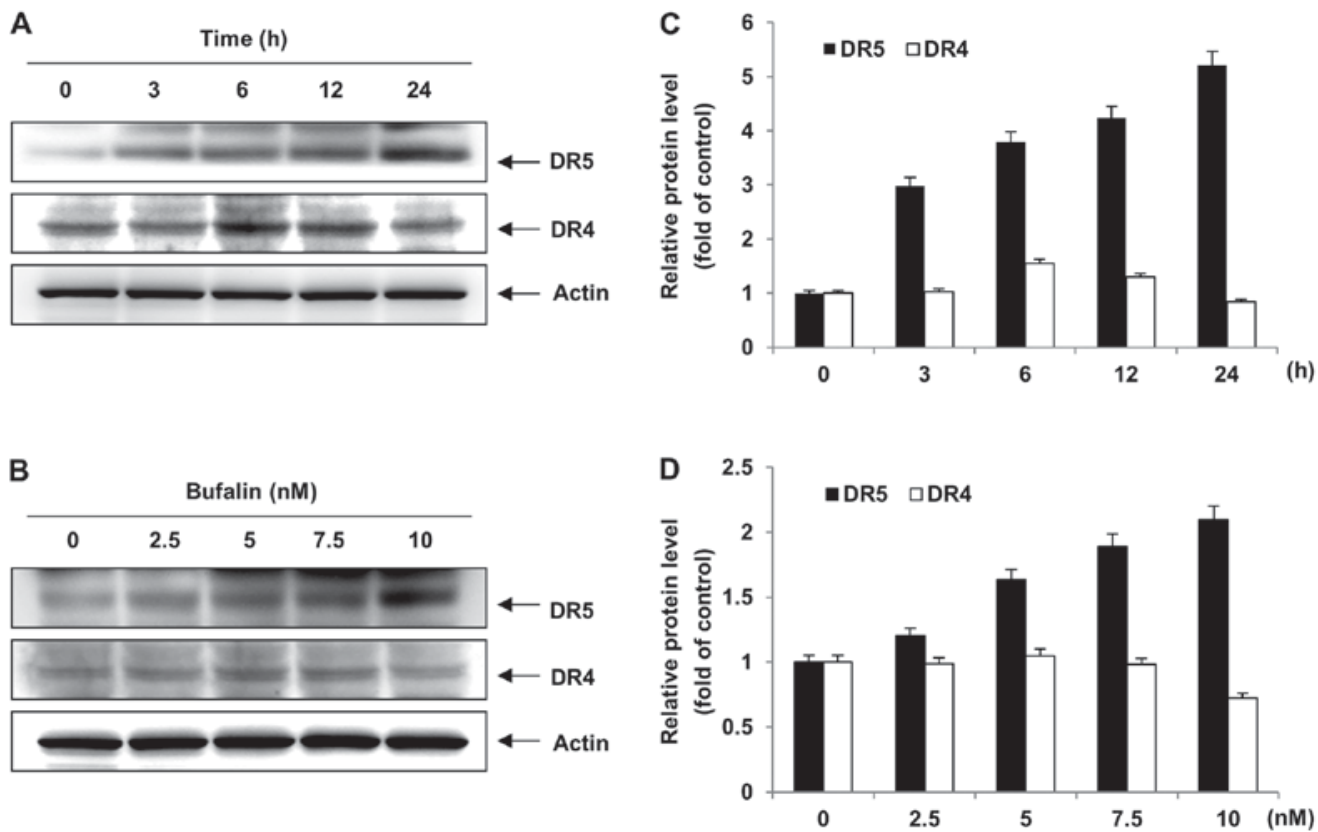

Figure 3. Involvement of DRs in apoptosis in human bladder cancer cells, induced by co-treatment with bufalin and tumor necrosis factor-related apoptosis-inducing ligand, analyzed by western blot. T24 cells were incubated with (A) $10 \mathrm{nM}$ bufalin for different time periods, or (B) with different concentrations of bufalin. The relative protein levels of DR4 and DR5 following (C) incubation with $10 \mathrm{nM}$ bufalin for different time periods or (D) incubation with different concentrations of bufalin are depicted. Actin was used as an internal control. The blots are representative of independent two experiments. DR, death receptor.

survival and distress signals (23). Treatment with bufalin or TRAIL alone, and the combination thereof, did not affect the expression levels of Bax or Bcl-2 proteins in T24 cells (Fig. 4). In contrast, the expression of Bid, a pro-apoptotic protein, was visibly decreased in response to combined treatment in T24 cells compared with the control (Fig. 4). The caspase inhibitor proteins XIAP and cFLIP were downregulated in T24 cells following combined bufalin and TRAIL treatment (Fig. 4). Consistently, the combination treatment increased DR5 protein levels, but not DR4 protein levels, compared with the control (Fig. 4). As a result, bufalin was demonstrated to sensitize T24 cells to TRAIL-mediated apoptosis via modulation of Bid, cFLIP, XIAP, and DR5 protein levels.

Activation of the caspases is synergistically induced by bufalin and TRAIL combination treatment in T24 cells. Activation of caspases works as a key regulator in the apoptosis signaling pathway (24). Thus, the involvement of various caspases during the bufalin and TRAIL-mediated apoptosis was 


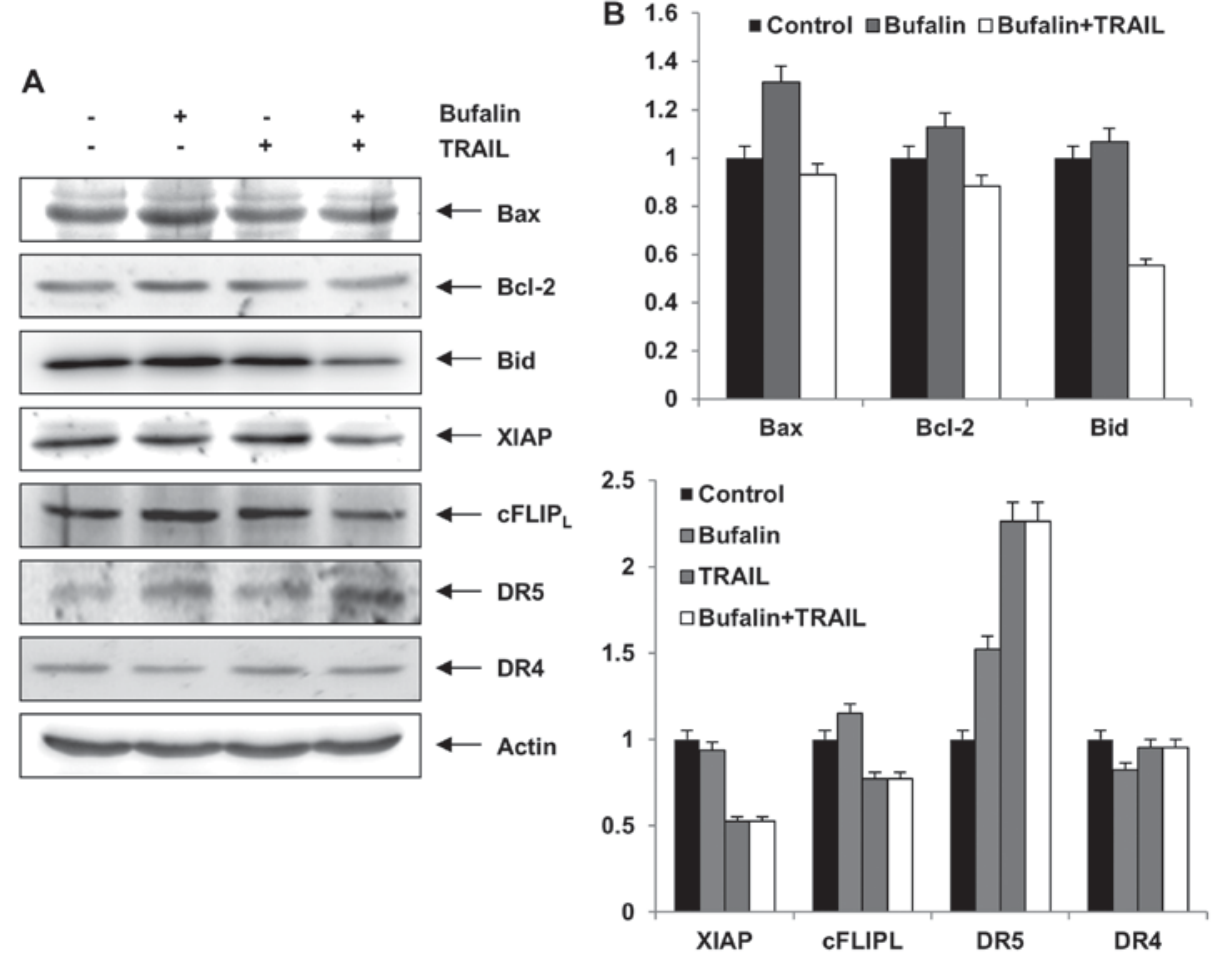

Figure 4. Effects of bufalin and TRAIL on the expression of apoptosis related proteins, as assessed by western blot. (A) T24 cells were incubated with bufalin $(10 \mathrm{nM})$, TRAIL $(50 \mathrm{ng} / \mathrm{ml})$ or a combination for $24 \mathrm{~h}$. Actin expression was used as a loading control. The blots are representative of three experiments (B) Relative levels of the indicated proteins. TRAIL, tumor necrosis factor-related apoptosis-inducing ligand; Bax, BCL2 associated X, apoptosis regulator; Bcl-2, B-cell lymphoma-2; Bid, BH3 interacting domain death agonist; XIAP, X-linked inhibitor of apoptosis protein; cFLIP, cellular Fas-associated death domain-like interleukin-1 $\beta$-converting enzyme inhibitory protein; DR, death receptor.
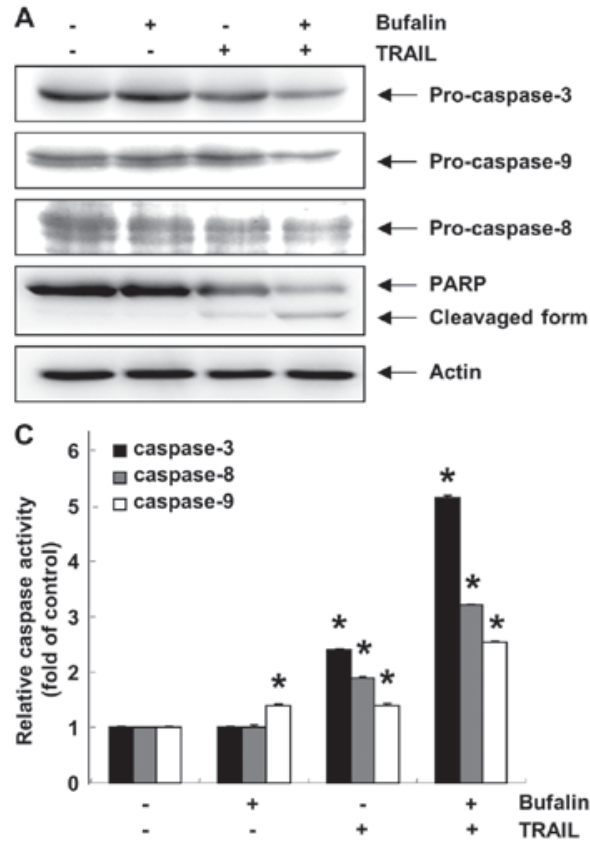

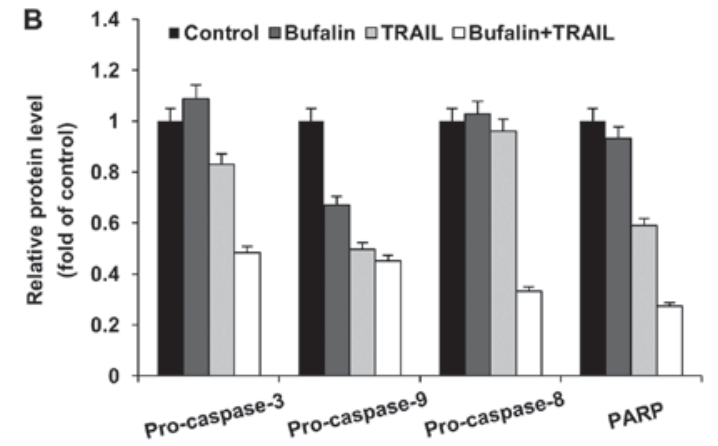

Figure 5. Effects of combined bufalin and TRAIL treatment on the activation of caspase and the cleavage of PARP. (A) T24 cells were incubated with bufalin $(10 \mathrm{nM})$, TRAIL $(50 \mathrm{ng} / \mathrm{ml})$, or a combination of both for $24 \mathrm{~h}$, and caspase and PARP levels were determined using western blot. (B) Relative levels of the indicated proteins. (C) Activity of caspase- $3,-8$ and -9 was determined using a caspase assay kit in T24 cells. The data are expressed as the mean \pm standard deviation of three independent experiments. The significance was determined using the Student's t-test. " $\mathrm{P}<0.05$ vs. untreated control. TRAIL, tumor necrosis factor-related apoptosis-inducing ligand; PARP, poly (ADP-ribose) polymerase.

assessed using a western blot analysis and an in vitro caspase activity test. Although treatment with bufalin or TRAIL did not induce proteolytic processing of caspases, a combination of bufalin and TRAIL effectively decreased pro-caspase-3, -8 and -9 levels in T24 cells (Fig. 5). PARP, which is a substrate protein of caspase-3, was visibly degraded following combined 
treatment in T24 cells. Next, cell lysates containing equal amounts of total protein from the cells treated with bufalin and TRAIL were analyzed for their in vitro caspase activity. Combined treatment with bufalin and TRAIL synergistically promoted caspase- $3,-8$ and -9 activity in T24 cells. Treatment with bufalin or TRAIL alone did not affect caspase-3 or -8 activity; $10 \mathrm{nM}$ bufalin treatment significantly altered caspase-9 activity, whereas treatment with TRAIL alone did not significantly affect caspase-9 (Fig. 5). These results indicated that caspases were involved in bufalin and TRAIL-mediated apoptosis in T24 cells.

\section{Discussion}

The purpose of the present study was to certify the potential of bufalin to overcome TRAIL-resistance in human bladder cancer cells. The T24 bladder cancer cell line was selected. In a previous sensitivity examination of three human bladder transitional cell cancer lines to TRAIL-mediated apoptosis, T24 cells (poorly differentiated) and 647V cells (moderately differentiated) demonstrated greater resistance than SW780 cells (well differentiated) (4). In another study, T24 cells and J82 cells demonstrated resistance to TRAIL, but 5637 cells were sensitive to TRAIL (25). From these previous studies, T24 cells have a well-established resistance to TRAIL. The data from the present study revealed that treatment consisting of a non-toxic dose of bufalin significantly promoted TRAIL-mediated apoptosis in T24 cell (Fig. 2).

Multiple mechanisms for bladder cancer cell escape from TRAIL-mediated apoptosis have been reported $(4,22,26,27)$. To determine the mechanisms by which bufalin mediated the susceptibility of bladder cancer cells to TRAIL, the expression of DRs, anti-apoptotic and pro-apoptotic proteins were investigated. In previous experimental studies, the restoration of sensitization to TRAIL-induced apoptosis in cancer cells has been associated with the downregulation of DRs $(4,22)$. In a clinical study, patients with bladder cancer with either a high DR4 or DR5 expression demonstrated evidence of a longer recurrence-free rate following operation than those with a low expression of the two (27). In particular, a number of studies have demonstrated that upregulating the expression of DR5 may be a more attractive target than DR4 to sensitize cancer cells to TRAIL $(2,28)$. In the present study, a combination of bufalin and TRAIL treatment significantly upregulated the expression of DR5 protein in T24 bladder cancer cells (Fig. 4). On the other hand, the expression of DR4 proteins remained almost unchanged, suggesting that increasing DR5 levels using anti-cancer drugs would lead to sensitization of the resistant tumor cells.

When TRAIL binds to DRs it forms the death-inducing signaling complex and leads to the activation of initiator caspases, including caspase-8, which is known as the death receptor pathway. This in turn activates the executioner caspases, including caspase-3, resulting in cell death $(28,29)$. In the present study, a combination of bufalin and TRAIL significantly induced the activation of caspase-3, -8 and -9 following the cleavage of PARP in T24 cells (Fig. 5). Furthermore, the activity of the three caspases was different. The activation of caspase- 3 stood out as being more important than the rest in T24 cells treated with bufalin and TRAIL. The activation levels of caspase- 8 and caspase- 3 were higher than caspase-9. These data suggested that the death receptor pathway was more closely associated with bufalin/TRAIL-induced apoptosis than the mitochondrial pathway. In addition, cFLIP is known to be an important anti-apoptotic regulator and resistance factor via suppressing death receptor-mediated apoptosis in multiple types of cancer cell $(30,31)$. Therefore, the effect of bufalin/TRAIL on cFLIP expression was evaluated. Treatment with bufalin and TRAIL downregulated the expression of cFLIP among the other anti-apoptotic and pro-apoptotic proteins, indicating that downregulation of cFLIP may have resulted in caspase-8 activation and apoptosis (Fig. 4) as previously described (30).

Taken together, the data from the present study demonstrated that a combination treatment of bufalin and TRAIL increased the level of death receptor DR5 and diminished the level of the anti-apoptotic protein cFLIP, which contributed to the activation of caspase-8. The pro-apoptotic protein Bid, through activated caspase- 8 , amplifies the apoptotic signal from DR5, but this combination is provided that a low dose of bufalin was able to overcome the resistance to TRAIL-mediated apoptosis in bladder cancer cells. Collectively, bufalin may be a novel anticancer drug and provide a different treatment option for patients with TRAIL-resistant bladder cancer.

\section{Acknowledgements}

The present study was supported by the Basic Science Research Program through the National Research Foundation of Korea, funded by the Korean government (grant nos. 2013R1A1A2065537, 2015R1A2A2A01004633 and 2016R1C1B2016529).

\section{References}

1. Trivedi R and Mishra DP: Trailing TRAIL resistance: Novel targets for TRAIL sensitization in cancer cells. Front Oncol 5: 69, 2015.

2. Thorburn A, Behbakht K and Ford H: TRAIL receptor-targeted therapeutics: Resistance mechanisms and strategies to avoid them. Drug Resist Updat 11: 17-24, 2008.

3. Dai X, Zhang J, Arfuso F, Chinnathambi A, Zayed ME, Alharbi SA, Kumar AP, Ahn KS and Sethi G: Targeting TNF-related apoptosis-inducing ligand (TRAIL) receptor by natural products as a potential therapeutic approach for cancer therapy. Exp Biol Med (Maywood) 240: 760-773, 2015.

4. Szliszka E, Mazur B, Zydowicz G, Czuba ZP and Król W: TRAIL-induced apoptosis and expression of death receptor TRAIL-R1 and TRAIL-R2 in bladder cancer cells. Folia Histochem Cytobiol 47: 579-585, 2009.

5. Lim B, Allen JE, Prabhu VV, Talekar MK, Finnberg NK and El-Deiry WS: Targeting TRAIL in the treatment of cancer: New developments. Expert Opin Ther Targets 19: 1171-1185, 2015.

6. Chen S, Fu L, Raja SM, Yue P, Khuri FR and Sun SY: Dissecting the roles of DR4, DR5 and c-FLIP in the regulation of Geranylgeranyltransferase I inhibition-mediated augmentation of TRAIL-induced apoptosis. Mol Cancer 9: 23, 2010.

7. Wang S and El-Deiry WS: TRAIL and apoptosis induction by TNF-family death receptors. Oncogene 22: 8628-8633, 2003.

8. Guancial EA, Roussel B, Bergsma DP, Bylund KC, Sahasrabudhe D, Messing E, Mohile SG and Fung C: Bladder cancer in the elderly patient: Challenges and solutions. Clin Interv Aging 10: 939-949, 2015.

9. Shamseddine A, Saleh A, Charafeddine M, Seoud M, Mukherji D, Temraz S and Sibai AM: Cancer trends in Lebanon: A review of incidence rates for the period of 2003-2008 and projections until 2018. Popul Health Metr 12: 4, 2014. 
10. Ahmed SM, Wu X, Jin X, Zhang X, Togo Y, Suzuki T, Li Y, Kanematsu A, Nojima M, Yamamoto S, et al: Synergistic induction of apoptosis by mapatumumab and anthracyclines in human bladder cancer cells. Oncol Rep 33: 566-572, 2015.

11. Ploeg M, Aben KK and Kiemeney LA: The present and future burden of urinary bladder cancer in the world. World J Urol 27 289-293, 2009

12. Yan S, Qu X, Xu L, Che X, Ma Y, Zhang L, Teng Y, Zou H and Liu Y: Bufalin enhances TRAIL-induced apoptosis by redistributing death receptors in lipid rafts in breast cancer cells. Anticancer Drugs 25: 683-689, 2014.

13. White-Gilbertson SJ, Kasman L, McKillop J, Tirodkar T, Lu P and Voelkel-Johnson C: Oxidative stress sensitizes bladder cancer cells to TRAIL mediated apoptosis by down-regulating anti-apoptotic proteins. J Urol 182: 1178-1185, 2009

14. LeBlanc H, Lawrence D, Varfolomeev E, Totpal K, Morlan J, Schow P, Fong S, Schwall R, Sinicropi D and Ashkenazi A: Tumor-cell resistance to death receptor-induced apoptosis through mutational inactivation of the proapoptotic Bcl-2 homolog Bax Nat Med 8: 274-281, 2002.

15. Shi YL, Feng S, Chen W, Hua ZC, Bian JJ and Yin W: Mitochondrial inhibitor sensitizes non-small-cell lung carcinoma cells to TRAIL-induced apoptosis by reactive oxygen species and Bcl-X(L)/p53-mediated amplification mechanisms. Cell Death Dis 5: e1579, 2014

16. Yin PH, Liu X, Qiu YY, Cai JF, Qin JM, Zhu HR and Li Q: Anti-tumor activity and apoptosis-regulation mechanisms of bufalin in various cancers: New hope for cancer patients. Asian Pac J Cancer Prev 13: 5339-5343, 2012.

17. Qi F, Li A, Inagaki Y, Kokudo N, Tamura S, Nakata M and Tang W: Antitumor activity of extracts and compounds from the skin of the toad Bufo bufo gargarizans Cantor. Int Immunopharmacol 11: 342-349, 2011.

18. Huang WW, Yang JS, Pai SJ, Wu PP, Chang SJ, Chueh FS Fan MJ, Chiou SM, Kuo HM, Yeh CC, et al: Bufalin induces G0/G1 phase arrest through inhibiting the levels of cyclin D, cyclin $\mathrm{E}, \mathrm{CDK} 2$ and CDK4, and triggers apoptosis via mitochondrial signaling pathway in T24 human bladder cancer cells. Mutat Res 732: 26-33, 2012.

19. Takai N, Ueda T, Nishida M, Nasu K and Narahara H: Bufalin induces growth inhibition, cell cycle arrest and apoptosis in human endometrial and ovarian cancer cells. Int J Mol Med 21: $637-643,2008$
20. Yeh JY, Huang WJ, Kan SF and Wang PS: Effects of bufalin and cinobufagin on the proliferation of androgen dependent and independent prostate cancer cells. Prostate 54: 112-124, 2003.

21. Yan S, Qu X, Xu C, Zhu Z, Zhang L, Xu L, Song N, Teng Y and Liu Y: Down-regulation of Cbl-b by bufalin results in up-regulation of DR4/DR5 and sensitization of TRAIL-induced apoptosis in breast cancer cells. J Cancer Res Clin Oncol 138: $1279-1289,2012$

22. Kelley RF, Totpal K, Lindstrom SH, Mathieu M, Billeci K, Deforge L, Pai R, Hymowitz SG and Ashkenazi A: Receptor-selective mutants of apoptosis-inducing ligand 2/tumor necrosis factor- related apoptosis-inducing ligand reveal a greater contribution of death receptor (DR) 5 than DR4 to apoptosis signaling. J Biol Chem 280: 2205-2212, 2005.

23. Yin XM: Signal transduction mediated by Bid, a pro-death Bcl-2 family proteins, connects the death receptor and mitochondria apoptosis pathways. Cell Res 10: 161-167, 2000.

24. Shalini S, Dorstyn L, Dawar S and Kumar S: Old, new and emerging functions of caspases. Cell Death Differ 22: 526-539, 2015.

25. Jin CY, Park C, Hwang HJ, Kim GY, Choi BT, Kim WJ and Choi YH: Naringenin up-regulates the expression of death receptor 5 and enhances TRAIL-induced apoptosis in human lung cancer A549 cells. Mol Nutr Food Res 55: 300-309, 2011.

26. Hong SH and Choi YH: Bufalin induces apoptosis through activation of both the intrinsic and extrinsic pathways in human bladder cancer cells. Oncol Rep 27: 114-120, 2012.

27. Li Y, Jin X, Li J, Jin X, Yu J, Sun X, Chu Y, Xu C, Li X, Wang X, et al: Expression of TRAIL, DR4, and DR5 in bladder cancer: Correlation with response to adjuvant therapy and implications of prognosis. Urology 79: 968.e7-e15, 2012.

28. Wu GS: TRAIL as a target in anti-cancer therapy. Cancer Lett 285: 1-5, 2009.

29. Chen Z, Sangwan V, Banerjee S, Chugh R, Dudeja V, Vickers SM and Saluja AK: Triptolide sensitizes pancreatic cancer cells to TRAIL-induced activation of the death receptor pathway. Cancer Lett 348: 156-166, 2014

30. Safa AR: c-FLIP, a master anti-apoptotic regulator. Exp Oncol 34: 176-184, 2012.

31. Ewald F, Ueffing N, Brockmann L, Hader C, Telieps T, Schuster M, Schulz WA and Schmitz I: The role of c-FLIP splice variants in urothelial tumours. Cell Death Dis 2: e245, 2011. 